Cronfa - Swansea University Open Access Repository

This is an author produced version of a paper published in :

Biochemistry

Cronfa URL for this paper:

http://cronfa.swan.ac.uk/Record/cronfa32994

\title{
Paper:
}

Loveridge, E., Hroch, L., Hughes, R., Williams, T., Davies, R., Angelastro, A., Luk, L., Maglia, G. \& Allemann, R. (2017). Reduction of Folate by Dihydrofolate Reductase from Thermotoga maritima. Biochemistry, 56(13), 18791886.

http://dx.doi.org/10.1021/acs.biochem.6b01268

This article is brought to you by Swansea University. Any person downloading material is agreeing to abide by the terms of the repository licence. Authors are personally responsible for adhering to publisher restrictions or conditions. When uploading content they are required to comply with their publisher agreement and the SHERPA RoMEO database to judge whether or not it is copyright safe to add this version of the paper to this repository. http://www.swansea.ac.uk/iss/researchsupport/cronfa-support/ 


\section{Reduction of Folate by Dihydrofolate Reductase from Thermotoga maritima}

E. Joel Loveridge, ${ }^{*}{ }^{\dagger, \ddagger}+0$ Lukas Hroch, ${ }^{\dagger, \S}$ Robert L. Hughes, ${ }^{\dagger}$ Thomas Williams, $^{\dagger}$ Rhidian L. Davies, $^{\dagger, \perp}$ Antonio Angelastro, ${ }^{\dagger}$ Louis Y. P. Luk, ${ }^{\dagger}$ Giovanni Maglia,

${ }^{\dagger}$ School of Chemistry, Cardiff University, Main Building, Park Place, Cardiff CF10 3AT, U.K.

${ }^{\ddagger}$ Department of Chemistry, Swansea University, Singleton Park, Swansea SA2 8PP, U.K.

${ }^{\S}$ Department of Pharmaceutical Chemistry and Drug Control, Faculty of Pharmacy in Hradec Kralove, Charles University in Prague, Akademika Heyrovskeho 1203, 50005 Hradec Kralove, Czech Republic

"School of Chemical Sciences, University of Birmingham, Edgbaston, Birmingham B15 2TT, U.K.

Supporting Information

ABSTRACT: Mammalian dihydrofolate reductases (DHFRs) catalyze the reduction of folate more efficiently than the equivalent bacterial enzymes do, despite typically having similar efficiencies for the reduction of their natural substrate, dihydrofolate. In contrast, we show here that DHFR from the hyperthermophilic bacterium Thermotoga maritima can catalyze reduction of folate to tetrahydrofolate with an efficiency similar to that of reduction of dihydrofolate under saturating conditions. Nuclear magnetic resonance and mass spectrometry experiments showed no evidence of the production of free dihydrofolate during either the EcDHFR- or TmDHFR-catalyzed reductions of folate,

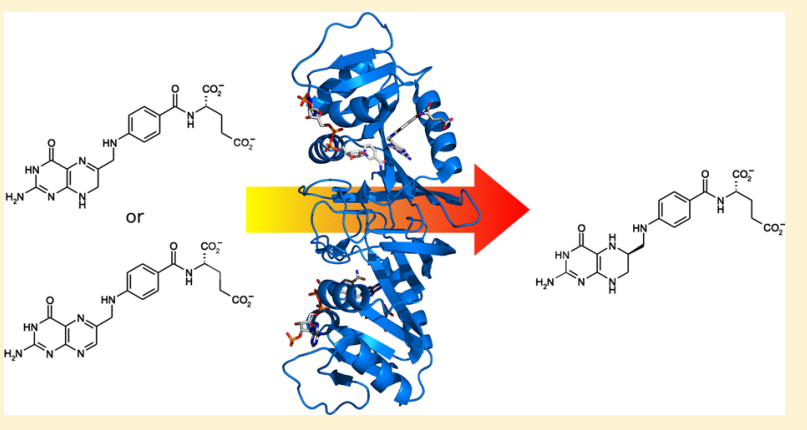
suggesting that both enzymes perform the two reduction steps without release of the partially reduced substrate. Our results imply that the reaction proceeds more efficiently in TmDHFR than in EcDHFR because the more open active site of TmDHFR facilitates protonation of folate. Because T. maritima lives under extreme conditions where tetrahydrofolate is particularly prone to oxidation, this ability to salvage folate may impart an advantage to the bacterium by minimizing the squandering of a valuable cofactor.

$\mathrm{D}$ ihydrofolate reductase (DHFR) is an essential enzyme in many organisms; it catalyzes the NADPH-dependent reduction of 7,8-dihydrofolate $\left(\mathrm{H}_{2} \mathrm{~F}\right)$ to 5,6,7,8-tetrahydrofolate $\left(\mathrm{H}_{4} \mathrm{~F}\right)$. Tetrahydrofolate is required for many one-carbon transfer reactions, most notably in the production of purines, deoxythymidine, glycine, methionine, and (in prokaryotes) pantothenic acid. As such, DHFR is an important drug target and is a clinical target for antibacterial, antimalarial, and anticancer therapies. Almost all known chromosomal DHFRs are monomeric enzymes; the structure, dynamics, and kinetics of the prototypic enzyme from Escherichia coli (EcDHFR) (Figure 1A) have been extensively studied. ${ }^{1-20}$ However, DHFR from the hyperthermophilic bacterium Thermotoga maritima (TmDHFR) forms an extremely stable homodimer $^{21,22}$ (Figure 1B) with a catalytic efficiency lower than that of monomeric DHFRs. ${ }^{23,24}$ Dimerization is important for the high thermostability of TmDHFR, but by itself, dimerization is not responsible for the catalytic activity of TmDHFR being lower than that of monomeric DHFRs. ${ }^{25-27}$ Instead, the more open nature of the active site renders the active site less protected from solvent, which leads to the reduction in catalytic activity. ${ }^{21,25-28}$
Interestingly, vertebrate DHFRs can reduce folate in addition to their natural substrate dihydrofolate. ${ }^{29}$ This allows the more stable folate to be used in the supplementation of foods to reduce the incidence of neural tube defects. ${ }^{30}$ Bacterial DHFRs, on the other hand, typically do not reduce folate efficiently. ${ }^{29}$ The folate specificity of EcDHFR can be increased by the introduction of loop regions from chicken DHFR ${ }^{31}$

In X-ray single-crystal structures of DHFR, folate and dihydrofolate bind almost identically to the enzyme. ${ }^{4}$ Therefore, both molecules present the re face of the pterin at C6 as the most likely candidate for attack by the $\mathrm{C} 4$ pro- $R$ hydride of $\mathrm{NADPH}$ (Figure 1B). Nuclear magnetic resonance (NMR) studies with DHFR from Lactobacillus casei (LcDHFR) indeed showed that when folate is fully reduced, both transferred hydrides are present on the same face of the product tetrahydrofolate. $^{32,33}$ Because initial reduction at C7 would require both an unfavorable hydride transfer geometry and protonation at the solvent-inaccessible $\mathrm{N} 8$, it has been suggested that the initial product of folate reduction is 5,6-

Received: December 16, 2016

Revised: $\quad$ March 9, 2017

Published: March 20, 2017 


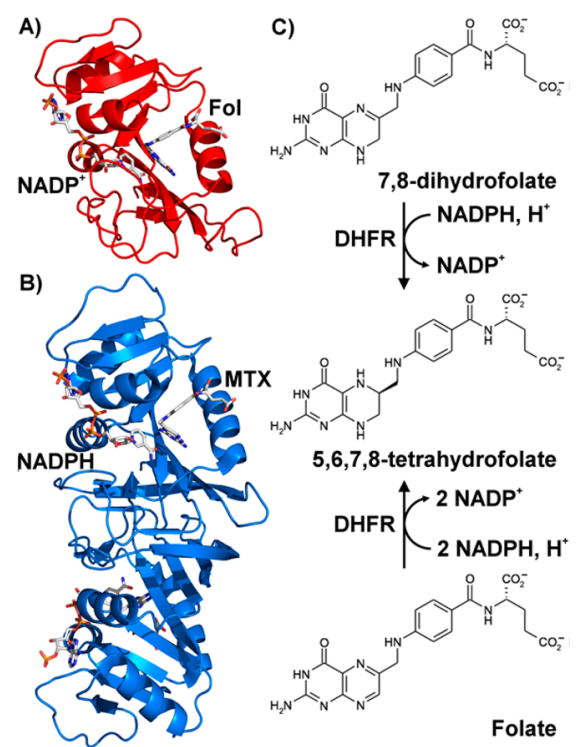

Figure 1. Cartoon representations of the crystal structures of (A) EcDHFR (PDB entry $1 \mathrm{RX}^{4}$ ) and (B) TmDHFR (PDB entry $\left.1 \mathrm{D} 1 \mathrm{G}^{21}\right)$, with bound ligands (MTX = methotrexate) shown as sticks, and (C) the DHFR-catalyzed reduction of dihydrofolate and folate to form tetrahydrofolate.

dihydrofolate, rather than the natural substrate 7,8-dihydrofolate, and that 5,6-dihydrofolate rearranges to form the more stable 7,8-dihydrofolate, presumably without leaving the active site of the enzyme, prior to the second reduction step. ${ }^{34-36}$ This is supported by neutron diffraction studies, which suggest that $\mathrm{N} 5$ of folate is protonated in the EcDHFR.NADP ${ }^{+}$. folate complex. ${ }^{37}$ It has been noted, however, that this does not solve the problem of N8 protonation, ${ }^{34,36}$ which is still required for the rearrangement of 5,6-dihydrofolate to 7,8-dihydrofolate, and that such apparently unavoidable difficulties in chemistry are the likely cause of the rates of folate reduction being lower than those of dihydrofolate reduction. Here, however, we show that in contrast to other bacterial DHFRs, TmDHFR catalyzes reduction of folate with an efficiency similar to that of reduction of dihydrofolate.

\section{MATERIALS AND METHODS}

Chemicals. $\mathrm{NADPH}, \mathrm{NADP}^{+}$, and isopropyl $\beta$-D-thiogalactopyranoside (IPTG) were purchased from Melford. Folate and $\left[{ }^{2} \mathrm{H}_{8}\right]$ isopropanol were purchased from Sigma. 7,8-Dihydrofolate was prepared by dithionite reduction of folate. ${ }^{38}$ EcDHFR, ${ }^{39,40}$ TmDHFR, $^{24,26}$ NADPD, ${ }^{39}$ and TbADH $^{39}$ were prepared as described previously. Reactant concentrations were determined spectrophotometrically using extinction coefficients of $6200 \mathrm{~cm}^{-1} \mathrm{M}^{-1}$ at $339 \mathrm{~nm}$ for NADPH and NADPD and $28000 \mathrm{~cm}^{-1} \mathrm{M}^{-1}$ at $282 \mathrm{~nm}$ for folate and dihydrofolate. ${ }^{41}$

Steady-State Kinetic Measurements. Steady-state turnover was monitored spectrophotometrically using a JASCO V660 spectrophotometer by following the decrease in absorbance at $340 \mathrm{~nm}\left[\varepsilon_{340}(\mathrm{NADPH}+\right.$ substrate $)=11800 \mathrm{M}^{-1} \mathrm{~cm}^{-1}$ in both cases $]^{31,42}$ in $100 \mathrm{mM}$ potassium phosphate $(\mathrm{pH} 7.0)$ containing $100 \mathrm{mM} \mathrm{NaCl}$ and $10 \mathrm{mM} \beta$-mercaptoethanol. The enzyme (0.05 $\mu \mathrm{M}$ EcDHFR or $0.1-1 \mu \mathrm{M}$ TmDHFR) was preincubated at the desired temperature with NADPH (1-100 $\mu \mathrm{M})$ for $1 \mathrm{~min}$ to prevent hysteresis prior to addition of dihydrofolate or folate $(1-100 \mu \mathrm{M})$. The change in initial rate with concentration was fit to the Michaelis-Menten equation using SigmaPlot 10. For KIE measurements on $k_{\text {cat }}, 100 \mu \mathrm{M}$ substrate and $100 \mu \mathrm{M}$ cofactor were used. Each data point is the result of three independent measurements.

Pre-Steady-State Kinetic Measurements. Single-turnover experiments were performed on an Applied Photophysics stopped-flow spectrophotometer, exciting the sample at $292 \mathrm{~nm}$ and observing the loss of fluorescence resonance energy transfer from the enzyme to $\mathrm{NADPH}$ during the reaction using a $400 \mathrm{~nm}$ cutoff output filter. The enzyme (final concentration of $20 \mu \mathrm{M})$ was preincubated with $\mathrm{NADPH}$ or NADPD (final concentration of $8 \mu \mathrm{M}$ ) for at least $5 \mathrm{~min}$ in 100 $\mathrm{mM}$ potassium phosphate buffer ( $\mathrm{pH} 7.0)$ containing $100 \mathrm{mM}$ $\mathrm{NaCl}$ and $10 \mathrm{mM} \beta$-mercaptoethanol. To determine the $\mathrm{pH}$ dependence of the single-turnover rate constants, MTEN buffer (50 mM morpholinoethanesulfonic acid, $25 \mathrm{mM}$ Tris, $25 \mathrm{mM}$ ethanolamine, $100 \mathrm{mM} \mathrm{NaCl}$, and $10 \mathrm{mM} \beta$-mercaptoethanol) was used. The reaction was initiated by rapidly mixing in folate (final concentration of $200 \mu \mathrm{M}$ ) in the same buffer at $20{ }^{\circ} \mathrm{C}$. Varying the concentrations of the reagents showed that the measured rate constants were limiting values. Each data point is the result of three independent measurements.

NMR Experiments. All NMR experiments were performed at $37{ }^{\circ} \mathrm{C}$ on a Bruker AVANCE III $600 \mathrm{MHz}\left({ }^{1} \mathrm{H}\right)$ spectrometer with a QCI-P cryoprobe. Spectra were recorded in $100 \mathrm{mM}$ potassium phosphate buffer $(\mathrm{pH}$ 7.0) containing 1 $\mathrm{mM} \mathrm{NaCl}$ and $10 \% \mathrm{D}_{2} \mathrm{O}$, using excitation sculpting for solvent suppression (pulse program zgesgp). Reference spectra were recorded for $\mathrm{NADPH}, \mathrm{NADP}^{+}$, folate, and dihydrofolate. A reference spectrum of a mixture of tetrahydrofolate and $\mathrm{NADP}^{+}$ was recorded following incubation of dihydrofolate and NADPH with EcDHFR for 5 min.

The TmDHFR-catalyzed reaction was monitored by mixing folate $(2.5 \mathrm{mM})$, NADPH ( $5 \mathrm{mM}, 2$ equiv), and TmDHFR (125 $\mu \mathrm{M}, 0.05$ equiv) in the NMR tube. For the EcDHFRcatalyzed reaction, $10 \mathrm{mM}$ folate, $20 \mathrm{mM} \mathrm{NADPH}$, and $1 \mathrm{mM}$ (0.1 equiv) EcDHFR were used. Solvent-suppressed onedimensional (1D) ${ }^{1} \mathrm{H}$ spectra (zgesgp) were recorded until no significant change in resonance intensity was observed, and a ${ }^{1} \mathrm{H}-{ }^{13} \mathrm{C}$ HSQC spectrum was then recorded. The reaction catalyzed by TmDHFR was performed in $50 \mathrm{mM}$ Tris buffer $(\mathrm{pH} 7.0)$ containing $1 \mathrm{mM} \mathrm{NaCl}$ and $10 \% \mathrm{D}_{2} \mathrm{O}$.

The high salt content of our NADPD led to low-quality NMR spectra. Therefore, to determine the hydride transfer face, a coupled enzyme assay was used to generate NADPD in situ. Folate $(2.5 \mathrm{mM})$, TmDHFR $(125 \mu \mathrm{M}, 0.05$ equiv $)$, $\mathrm{TbADH}$ (1 $\mathrm{mg}$ of freeze-dried enzyme $\left.{ }^{39}\right)$, and $\left[{ }^{2} \mathrm{H}_{8}\right]$ isopropanol $(25 \mu \mathrm{L}, \sim 570 \mu \mathrm{M}, 0.23$ equiv; also used to provide the lock signal) were mixed in $50 \mathrm{mM}$ Tris buffer $(\mathrm{pH}$ 7.0) containing $1 \mathrm{mM} \mathrm{NaCl}$ (final volume of $500 \mu \mathrm{L}$ ). Larger volumes of $\left[{ }^{2} \mathrm{H}_{8}\right]$ isopropanol caused precipitation over time, which led to poor NMR spectra. The reaction was initiated by addition of $\mathrm{NADP}^{+}(250 \mu \mathrm{M}, 0.1$ equiv $)$, and solventsuppressed 1D ${ }^{1} \mathrm{H}$ spectra (zgesgp) and ${ }^{1} \mathrm{H}-{ }^{13} \mathrm{C}$ HSQC spectra were recorded over $3 \mathrm{~h}$. Reference ${ }^{1} \mathrm{H}$ and ${ }^{1} \mathrm{H}-{ }^{13} \mathrm{C}$ HSQC spectra of $6-\left[{ }^{2} \mathrm{H}\right]$ tetrahydrofolate were recorded using this coupled assay with dihydrofolate and EcDHFR instead of folate and TmDHFR.

Liquid Chromatography-Mass Spectrometry (LCMS) Analysis. The reaction was also monitored by LC-MS using a Waters Synapt G2-Si time-of-flight mass spectrometer coupled to a Waters Acquity UPLC system with an Acquity $\mathrm{C} 18$ reverse phase column held at $40{ }^{\circ} \mathrm{C}$ throughout the run. Reactions were performed by mixing folate $(50 \mu \mathrm{M}), \mathrm{NADPH}$ 
(100 $\mu \mathrm{M})$, and TmDHFR $(2.5 \mu \mathrm{M}, 0.05$ equiv) or EcDHFR (5 $\mu \mathrm{M}, 0.1$ equiv) in $50 \mathrm{mM}$ Tris buffer ( $\mathrm{pH} 7.0)$ containing 1 $\mathrm{mM} \mathrm{NaCl}$ and $10 \mathrm{mM} \beta$-mercaptoethanol. Reactions were allowed to proceed to $\sim 50 \%$ completion (as determined by UV at $340 \mathrm{~nm}$ ) before the enzyme was removed using a $12 \mathrm{kDa}$ cutoff filter and $1 \mu \mathrm{L}$ of the filtrate was injected onto the column. UV spectroscopy showed that folate, dihydrofolate, and tetrahydrofolate concentrations were not affected by the filtration step. Compounds were eluted using a gradient from 5 to $95 \%$ aqueous acetonitrile (containing $0.1 \%$ formic acid) over $10 \mathrm{~min}$, and mass spectra were recorded from $\mathrm{m} / z 100$ to 1000 in ESP+Ve mode. The reactions and analysis were performed in duplicate. All processing was performed using MassLynx version 4.1. Extracted ion chromatograms were taken with ions at $m / z 442$ and 446 for folate and tetrahydrofolate, respectively. For dihydrofolate, ions at $\mathrm{m} / z 444$ and 297 were sought, but not detected, in all chromatograms. To confirm that dihydrofolate was detectable, dihydrofolate $(10 \mu \mathrm{M})$ was added to a post-LC-MS sample and the analysis repeated.

\section{RESULTS AND DISCUSSION}

Steady-State and Single-Turnover Kinetics. MichaelisMenten kinetics for folate and dihydrofolate were measured with EcDHFR and TmDHFR at $20{ }^{\circ} \mathrm{C}$ and $\mathrm{pH} 7$ (Figure S1). Although, in line with previous observations, EcDHFR gave a $k_{\text {cat }}$ with folate $\sim 5000$-fold lower than that with dihydrofolate, ${ }^{31}$ the $k_{\text {cat }}$ for TmDHFR-catalyzed folate reduction was only $\sim 3$ fold lower than for dihydrofolate (Table 1). The primary

Table 1. Kinetic Parameters at $20^{\circ} \mathrm{C}$ for EcDHFR and TmDHFR with $\mathrm{H}_{2} \mathrm{~F}$ and Folate

\begin{tabular}{lccc}
$\begin{array}{c}\text { enzyme, } \\
\text { substrate }\end{array}$ & $K_{\mathrm{M}}(\mu \mathrm{M})$ & $k_{\text {cat }}\left(\mathrm{s}^{-1}\right)$ & $k_{\mathrm{H}}\left(\mathrm{s}^{-1}\right)$ \\
EcDHFR, $\mathrm{H}_{2} \mathrm{~F}$ & $0.90 \pm 0.06$ & $11.1 \pm 0.1$ & $159.8 \pm 7.9^{18}$ \\
EcDHFR, folate & $8.77 \pm 0.70$ & $0.0022 \pm 0.0005$ & not determined \\
TmDHFR, $\mathrm{H}_{2} \mathrm{~F}$ & $<0.5$ & $0.091 \pm 0.02$ & $0.122 \pm 0.003^{44}$ \\
$\begin{array}{c}\text { TmDHFR, } \\
\text { folate }\end{array}$ & $6.23 \pm 0.70$ & $0.0332 \pm 0.001$ & $0.053 \pm 0.001$ \\
\hline
\end{tabular}

kinetic isotope effect (KIE) on TmDHFR-catalyzed transfer of hydride to folate, obtained by comparing the $k_{\text {cat }}$ observed with NADPH with that observed with $4 R-\left({ }^{2} \mathrm{H}\right)-\mathrm{NADPH}$ (NADPD), was $3.56 \pm 0.52$. In addition, the single-turnover rate constant $k_{\mathrm{H}}$ for TmDHFR-catalyzed folate reduction, which reports predominantly on the chemical step of the catalytic cycle, was only slightly higher than the steady-state rate constant (Table 1 ). This demonstrates that the chemical step of the catalytic cycle is predominantly rate-limiting, as seen previously for dihydrofolate. $^{24}$ Under saturating conditions, TmDHFR can therefore reduce folate with an efficiency similar to that of dihydrofolate. However, as the $K_{M}$ for folate with TmDHFR is substantially higher than that of dihydrofolate (Table 1), the $k_{\text {cat }} / K_{\mathrm{M}}$ for folate is lower than that for dihydrofolate. The reduced affinity for folate relative to that for dihydrofolate seen for TmDHFR is consistent with results obtained with LcDHFR $^{43}$ and EcDHFR. ${ }^{31}$

The temperature dependence of the primary kinetic isotope effect (KIE) on TmDHFR-catalyzed hydride transfer to folate was also determined at $\mathrm{pH}$ 7. Single-turnover rate constants observed with NADPH as a cofactor were compared with those observed with NADPD. At all temperatures, the KIE with folate as a substrate was not significantly different from that observed previously with dihydrofolate ${ }^{44}$ (Figure 2 and Tables S1-S3). Furthermore, the apparent $\mathrm{p} K_{\mathrm{a}}$ for the reaction with folate was
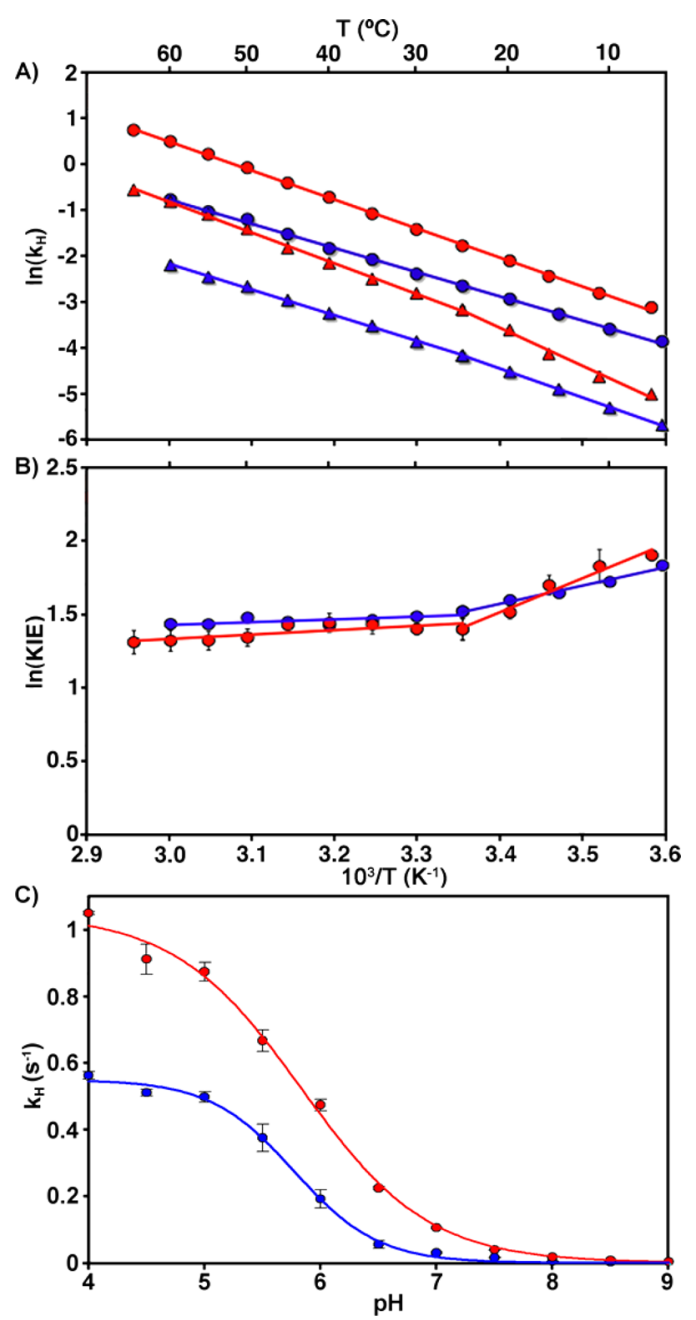

Figure 2. (A) Arrhenius plots for the transfer of hydride (circles) and deuteride (triangles) from NADPH/D to $\mathrm{H}_{2} \mathrm{~F}$ (red) ${ }^{44}$ and folate (blue) catalyzed by TmDHFR under single-turnover conditions at $\mathrm{pH}$ 7. (B) Plots of the KIE on a logarithmic abscissa vs the inverse temperature at $\mathrm{pH} 7$ for $\mathrm{H}_{2} \mathrm{~F}$ (red) ${ }^{44}$ and folate (blue). (C) $\mathrm{pH}$ dependence of the hydride transfer rate constant at $25{ }^{\circ} \mathrm{C}$ for $\mathrm{H}_{2} \mathrm{~F}$ (red) ${ }^{55}$ and folate (blue).

$5.77 \pm 0.03$, similar to the value of $5.83 \pm 0.06$ observed with dihydrofolate $^{25}$ (Figure 2 and Table S4). In EcDHFR, the $\mathrm{pH}$ dependence of the single-turnover rate constant is determined by the $\mathrm{p} K_{\mathrm{a}}$ of protonated dihydrofolate within the active site of the enzyme (6.5), which is elevated substantially from its solution value. ${ }^{45}$ Although the $\mathrm{p} K_{\mathrm{a}}$ of protonated dihydrofolate within the active site of TmDHFR has not been experimentally verified, the $\mathrm{pH}$ dependence of the TmDHFR-catalyzed reaction is likely also to be determined by this value. We have previously suggested that the lower apparent $\mathrm{p} K_{\mathrm{a}}$ for the TmDHFR-catalyzed reaction is due to the more open, ${ }^{21}$ and therefore solvent-accessible, active site, which prevents such extensive modulation of the substrate $\mathrm{p} K_{\mathrm{a}}{ }^{28}$ As both proposed mechanisms require $\mathrm{N} 8$ protonation before the second reduction event, the similar $\mathrm{p} K_{\mathrm{a}}$ values for the reactions with folate and dihydrofolate suggest that TmDHFR can modulate the $\mathrm{p} K_{\mathrm{a}}$ at $\mathrm{N} 8$ of folate quite efficiently. It may be that the more solvent-accessible active site in TmDHFR actually facilitates N8 


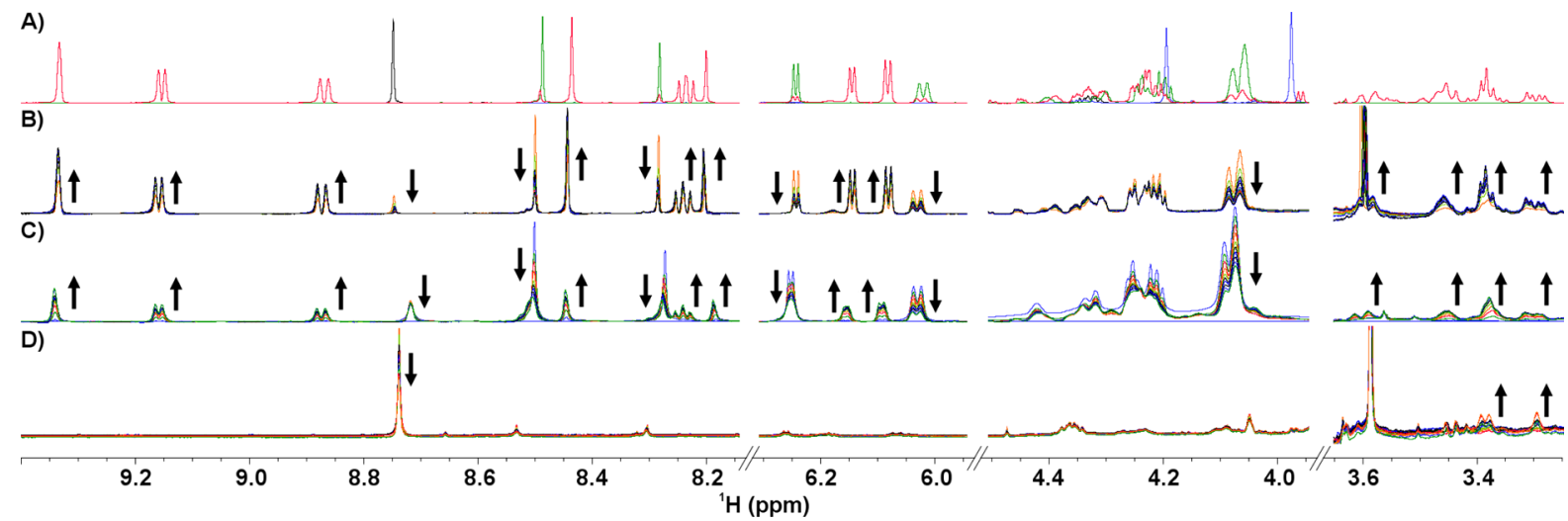

Figure 3. Key regions of the (A) ${ }^{1} \mathrm{H}$ NMR spectra of folate (black), $\mathrm{H}_{2} \mathrm{~F}$ (blue), NADPH (green), and a mixture of NADP ${ }^{+}$and $\mathrm{H}_{4} \mathrm{~F}$ (red), and of ${ }^{1} \mathrm{H}$ NMR spectra acquired during reduction of folate using NADPH in the presence of (B) TmDHFR and (C) EcDHFR, and (D) using in situgenerated NADPD in the presence of TmDHFR. In panels B and D, the sharp singlet at $\sim 3.6 \mathrm{ppm}$ is a ${ }^{13} \mathrm{C}$ satellite from the buffer resonance. The region from 3.25 to $3.65 \mathrm{ppm}$, which contains the $\mathrm{H}_{4} \mathrm{~F} \mathrm{H}, \mathrm{H} 7$, and $\mathrm{H} 9$ resonances, is shown at $4 \times$ magnification in panels $\mathrm{B}-\mathrm{D}$.

protonation, by providing solvent-mediated routes to protonation and cation stabilization not available in DHFRs with more tightly closed active sites. A number of crystallographic water molecules are seen in the folate-binding site of TmDHFR in complex with $\mathrm{NADP}^{+}$and methotrexate (PDB entry $1 \mathrm{D} 1 \mathrm{G}$ ), including some buried within the active site pocket. ${ }^{21}$ Given the low flexibility and paucity of histidine residues in TmDHFR, ${ }^{21}$ a $\mathrm{pH}$-dependent conformational change, as seen for apoEcDHFR, ${ }^{46}$ seems less likely.

It was not possible to obtain a value for $k_{\mathrm{H}}$ from singleturnover kinetic data with EcDHFR. Although a small loss of fluorescence was observed over short time scales, with a rate constant of $571.5 \pm 43.0 \mathrm{~s}^{-1}$ at $20{ }^{\circ} \mathrm{C}$, a kinetic isotope effect of 1 was observed, demonstrating that the event causing this loss of fluorescence was not the chemical step of the catalytic cycle. A subsequent increase in fluorescence at longer time scales meant that $k_{\mathrm{H}}$ could not be determined.

NMR Experiments. NMR experiments were performed to confirm that EcDHFR and TmDHFR convert folate to tetrahydrofolate and to determine whether any free dihydrofolate is produced. EcDHFR-catalyzed reduction of dihydrofolate led to a loss of the strong singlet resonances for the two $\mathrm{H} 7$ protons and the two $\mathrm{H} 9$ protons, and the appearance of four new multiplets for $\mathrm{H} 6, \mathrm{H} 7_{\mathrm{R}}, \mathrm{H} 7_{\mathrm{S}}$ and the two $\mathrm{H} 9$ protons of tetrahydrofolate as expected ${ }^{32,33}$ (Figure 3A).

Incubation of folate and NADPH in the presence of 0.05 equiv of TmDHFR led to loss of resonances corresponding to these compounds and growth of resonances corresponding to tetrahydrofolate and $\mathrm{NADP}^{+}$(Figure 3B), confirming that tetrahydrofolate was formed by the TmDHFR-catalyzed reduction of folate. For EcDHFR, 4-fold higher concentrations of folate and NADPH and 0.1 equiv of the enzyme were required before useful results could be obtained. Tetrahydrofolate and $\mathrm{NADP}^{+}$resonances were visible after a few hours, although the intensities of the folate and NADPH resonances were not greatly diminished (Figure 3C), as expected from the poor efficiency of EcDHFR-catalyzed folate reduction. Additional time led to a further decrease in the intensity of the folate and NADPH resonance and an increase in the intensity of the $\mathrm{NADP}^{+}$resonance, although the intensity of the tetrahydrofolate resonance did not increase further and spectral quality was diminished, presumably because of oxidation of the tetrahydrofolate. For both enzymes, the decrease in the integral for $\mathrm{NADPH}$ and folate loss, and the increase in the integral for
$\mathrm{NADP}^{+}$, are proportional to one another (Figure 3B,C). As $\mathrm{NADPH}$ and folate are present in a 2:1 ratio, this shows that they are depleted in a 2:1 ratio as expected.

No resonances corresponding to dihydrofolate were observed for either enzyme at any time during the experiment (Figure 3). As the reactions were performed with saturating concentrations of $\mathrm{NADPH}$ and folate, then if dihydrofolate were released from the enzyme during the catalytic cycle, the high folate concentration would favor folate binding over dihydrofolate rebinding, and consequently reduction of folate that was more rapid than that of dihydrofolate. This in turn would lead to a buildup of dihydrofolate. When a 1:1 folate/ dihydrofolate mixture was used, both enzymes preferentially catalyzed reduction of dihydrofolate (Figure S2), as expected from our kinetic results. However, the dihydrofolate released from the enzyme is unlikely to successfully compete with the saturating folate for the active site under the experimental conditions. The NMR experiments therefore strongly suggest that dihydrofolate is not released from the active site of the enzyme.

To determine the face of folate on which the two hydride transfers take place, a coupled enzyme assay was used to generate NADPD in situ. TmDHFR was incubated with folate in the presence of $\mathrm{NADP}^{+},\left[{ }^{2} \mathrm{H}_{8}\right]$ isopropanol, and alcohol dehydrogenase from Thermoanaerobacter brockii (TbADH). On the basis of our previous work with TmDHFR in organic cosolvents, isopropanol is not expected to have a significant impact on TmDHFR catalysis at the concentrations used, ${ }^{47}$ although reaction rates were reduced because of the KIE on the reaction (vide supra), leading to poorer tetrahydrofolate signals. As observed previously for LcDHFR, ${ }^{32,33}$ signals corresponding to $\mathrm{H} 6$ and $\mathrm{H} 7$ resonances were not seen in the ${ }^{1} \mathrm{H}$ NMR spectrum or the ${ }^{1} \mathrm{H}-{ }^{13} \mathrm{C}$ HSQC of the tetrahydrofolate product (Figures 3D and 4), confirming that the transfer of hydride to both sites on folate occurred on the same face.

LC-MS Analysis. LC-MS analysis was used to provide further evidence of tetrahydrofolate production without formation of free dihydrofolate. Following incubation of folate and NADPH with TmDHFR and EcDHFR, peaks corresponding to $\mathrm{NADP}^{+}$and tetrahydrofolate could clearly be observed, although retention times were varied slightly between runs (Figure 5 and Figures S3-S6). Extracted ion chromatograms revealed no evidence of dihydrofolate (Figures S7-S9). However, repetition of the LC-MS analysis following addition 


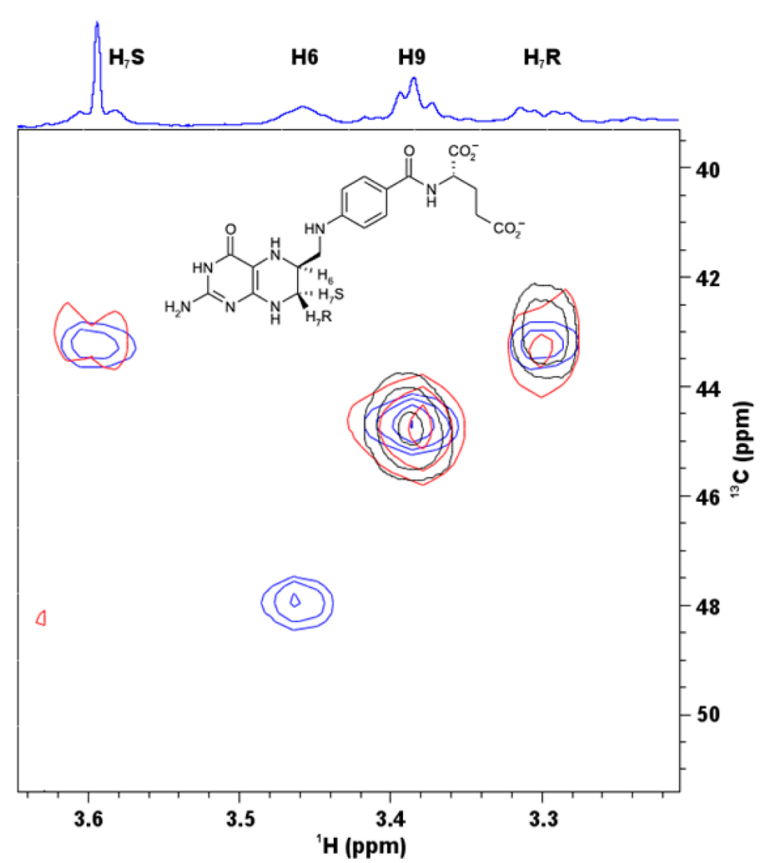

Figure 4. ${ }^{1} \mathrm{H}-{ }^{13} \mathrm{C}$ HSQC spectra of the $\mathrm{H} 6 / \mathrm{H} 7 / \mathrm{H} 9$ region of tetrahydrofolate produced using TmDHFR with folate and NADPH (blue), EcDHFR with dihydrofolate and NADPD (red), and TmDHFR with folate and NADPD (black). The ${ }^{1} \mathrm{H}$ projection shown is for tetrahydrofolate produced using NADPH, with assignments taken from refs 32 and 33. The sharp singlet at $\sim 3.6$ $\mathrm{ppm}$ in the projection is a ${ }^{13} \mathrm{C}$ satellite from the buffer resonance, coincident with the $\mathrm{H}_{7} \mathrm{~S}$ resonance, and is not responsible for the observed cross-peak.
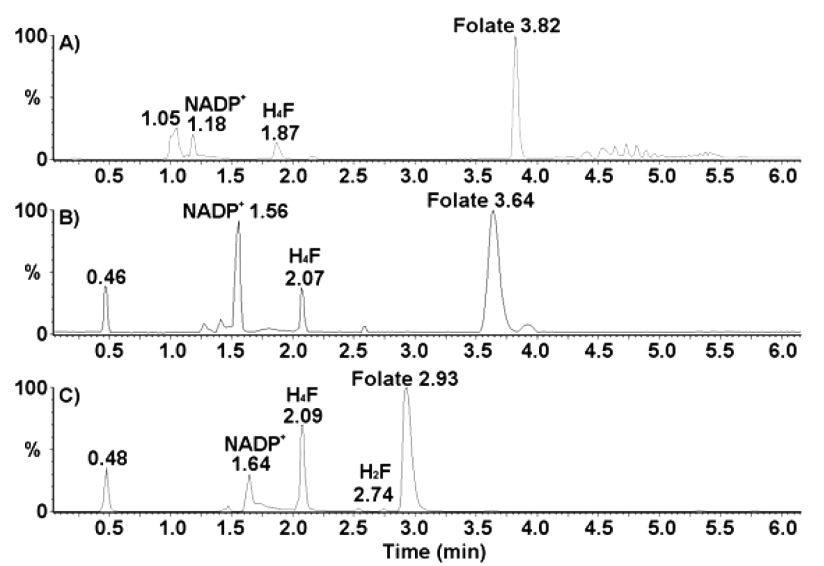

Figure 5. LC-MS analysis of DHFR-catalyzed folate reduction. Chromatograms are shown at $\sim 50 \%$ completion (by UV) for the reaction catalyzed by (A) EcDHFR and (B) TmDHFR and (C) for reinjection of the TmDHFR postreaction sample with addition of dihydrofolate. Extracted ion chromatograms and mass spectra are shown in Figures S3-S9.

of dihydrofolate showed that this compound could be easily detected by our system (Figure 5C and Figures S7-S9). The sensitivity of LC-MS compared to NMR confirms that no free dihydrofolate is produced during the reduction of folate by either enzyme. As, like the NMR experiments described above, these reactions were performed with saturating concentrations of NADPH and folate, this demonstrates that dihydrofolate is not released from the active site of the enzyme.
Reduction of Folate by EcDHFR and TmDHFR. For both enzymes, no free dihydrofolate was observed during the reaction. This strongly suggests that dihydrofolate is not released from the active site of either enzyme but that the catalytic cycle continues via release of $\mathrm{NADP}^{+}$to form the DHFR: $\mathrm{H}_{2} \mathrm{~F}$ binary complex followed by rebinding of $\mathrm{NADPH}$ to form the DHFR:NADPH: $\mathrm{H}_{2} \mathrm{~F}$ Michaelis complex. This is to be expected for EcDHFR from published kinetic data (Figure $6)^{1,31}$ and from the fact that folate and NADPH were both present at high concentrations in our reactions. In E. coli, the concentration of $\mathrm{NADPH}$ is $12 \mu \mathrm{M},{ }^{48}$ higher than the dissociation constant and the Michaelis constant of $\mathrm{NADPH},{ }^{1,49}$ and likely still sufficient for NADPH rebinding to be preferred to dihydrofolate loss. Although concentrations of folates ${ }^{50-52}$ are likely to be below the Michaelis constant for dihydrofolate, ${ }^{1,53}$ this will not affect the preferred catalytic cycle if NADPH concentrations are sufficiently high. Although the intracellular concentrations of NADPH and dihydrofolate in $T$. maritima are not known, TmDHFR has an affinity for the reactants higher than that of EcDHFR, making it more likely that the NADPH concentration will be saturating. In addition, the rate constants for binding events in TmDHFR will be even higher than those of release events. The data obtained here also suggest that, as seen for EcDHFR, ${ }^{1,31}$ the rate constants for the release of product from the TmDHFR:NADP ${ }^{+} \mathrm{H}_{2} \mathrm{~F}$ and TmDHFR:NADP ${ }^{+}: \mathrm{H}_{4} \mathrm{~F}$ complexes are substantially smaller than those for $\mathrm{NADP}^{+}$release.

There are a number of possible explanations for the greater rate of folate reduction by TmDHFR compared to that of EcDHFR. If the initial reduction occurs at C6, then TmDHFR must be better able to catalyze the rearrangement of 5,6dihydrofolate to 7,8-dihydrofolate (by N5 deprotonation, 1,2hydride shift from $\mathrm{C} 6$ to $\mathrm{C} 7$, and N8 protonation) prior to the second reduction. As both reduction steps show a substantial primary KIE on NADPH oxidation, this rearrangement must be fast compared to the hydride transfer events. Alternatively, if the initial reduction occurs at $\mathrm{C} 7$, then TmDHFR must be better able to support the arrangement of reactants required for this, and/or better able to support protonation at N8. The common feature is protonation of N8. As discussed above, the similarity in the apparent $\mathrm{p} K_{\mathrm{a}}$ values for the two reduction steps suggests that TmDHFR can modulate the $\mathrm{p} K_{\mathrm{a}}$ at $\mathrm{N} 8$ of folate quite efficiently. It may therefore be that, with its less solventaccessible active site, EcDHFR fails to modulate the $\mathrm{pK}$ of folate so efficiently, and rates of folate reduction will be greater at lower $\mathrm{pH}$. Unfortunately, as we were unable to measure a rate constant for EcDHFR-catalyzed hydride transfer to folate, we cannot test this.

\section{CONCLUSIONS}

TmDHFR catalyzes the reduction of folate to tetrahydrofolate with an efficiency similar to that of the reduction of dihydrofolate under saturating conditions. The similar primary KIE on hydride transfer and its temperature dependence suggest that the nature of the chemical step is similar to those of the two substrates. Furthermore, no evidence of the production of free dihydrofolate was seen for the EcDHFRor TmDHFR-catalyzed reduction of folate, suggesting that both enzymes perform the two reduction steps without release of the partially reduced substrate. It had previously been shown that EcDHFR may be engineered to increase specificity for folate, although this does not increase the $k_{\text {cat }}{ }^{31}$ likely because the necessary protonation of folate at $\mathrm{N} 8$ is unfavorable within the 


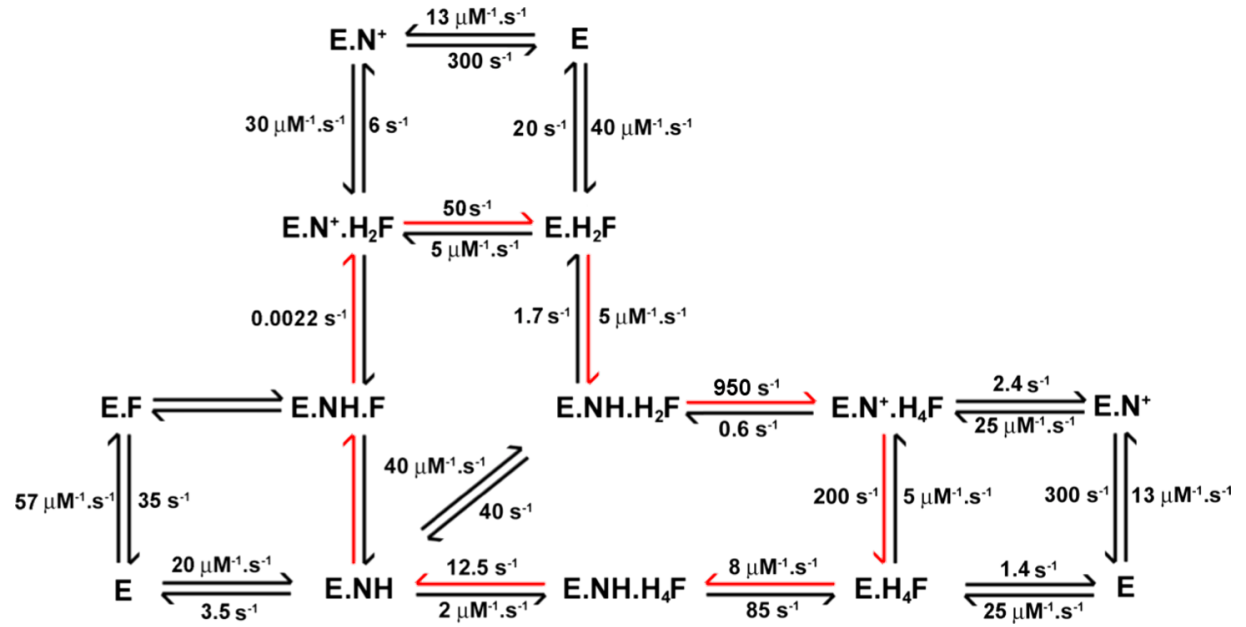

Figure 6. Kinetic scheme for the EcDHFR-catalyzed reduction of folate, adapted from ref 1 (all values except on/off and hydride transfer rate constants for folate) and ref 31 (folate on/off rate constants). E represents the enzyme (DHFR). NH represents NADPH. $\mathrm{N}^{+}$represents NADP ${ }^{+}$. F represents folate. The preferred catalytic cycle in the presence of saturating folate and NADPH is colored red.

active site. While our results do not shed light on whether initial reduction of folate occurs at $\mathrm{C} 6$ or $\mathrm{C} 7$, they suggest that the reaction proceeds more efficiently in TmDHFR than in EcDHFR because the more open active site of TmDHFR facilitates protonation of folate.

The only likely source of folate for T. maritima is oxidation of reduced folates. T. maritima lives in deep-sea vents and thermal springs, often at temperatures above $90{ }^{\circ} \mathrm{C},{ }^{54}$ and under these conditions, the oxidation-prone tetrahydrofolate is particularly vulnerable to degradation. Given that oxidation may also be mediated by species other than $\mathrm{O}_{2}$, the increased efficiency of folate reduction may therefore represent a salvage pathway allowing the bacterium to minimize squandering of this valuable cofactor, thereby gaining an additional competitive advantage under these challenging conditions for life.

\section{ASSOCIATED CONTENT}

\section{S Supporting Information}

The Supporting Information is available free of charge on the ACS Publications website at DOI: 10.1021/acs.biochem.6b01268.

Michaelis-Menten curves, additional NMR spectra, mass spectra and extracted ion chromatograms from LC-MS, tabulated data of the temperature dependence of $k_{\mathrm{H}}, k_{\mathrm{cat}}$, and the $\mathrm{KIE}$ on $k_{\mathrm{H}}$ at $\mathrm{pH} 7$, activation energies and Arrhenius prefactors, and the $\mathrm{pH}$ dependence of $k_{\mathrm{H}}$ (PDF)

\section{AUTHOR INFORMATION}

\section{Corresponding Authors}

*School of Chemistry, Cardiff University, Main Building, Park Place, Cardiff CF10 3AT, U.K. Phone: +44 (0)29 20879014.

E-mail: allemannrk@cardiff.ac.uk.

*Department of Chemistry, Swansea University, Singleton Park, Swansea SA2 8PP, U.K. E-mail: e.j.loveridge@swansea.ac. uk. Phone: +44 (0)1792 513199.

\section{ORCID $\odot$}

E. Joel Loveridge: 0000-0002-8528-4019

Rudolf K. Allemann: 0000-0002-1323-8830

\section{Present Addresses}

${ }^{\perp}$ R.L.D.: EQ Ltd. Process Consultancy Services, Beechwood House, Christchurch Road, Newport NP19 8AJ, U.K.

${ }^{\circledR}$ G.M.: Groningen Biomolecular Sciences and Biotechnology Institute, University of Groningen, Nijenborgh 4, 9747 AG Groningen, The Netherlands.

\section{Author Contributions}

E.J.L., L.H., R.L.H., T.W., R.L.D., A.A., L.Y.P.L., and G.M. all performed experimental work. E.J.L. and R.K.A. wrote the manuscript.

\section{Notes}

The authors declare no competing financial interest. Information about the LC-MS data that underpin the results presented in this article, including how to access them, can be found in the Cardiff University data catalogue at http:// doi.org/10.17035/d.2017.0033099548.

\section{ACKNOWLEDGMENTS}

This work was supported by the U.K. Biotechnology and Biological Sciences Research Council (BBSRC) through Grants BB/E008380/1 and BB/J005266/1 (to R.K.A.), by the U.K. Engineering and Physical Sciences Research Council (EPSRC) through Grant EP/L027240/1, by the Life Sciences Research Network Wales (an initiative funded through the Welsh Government's Sêr Cymru program) (studentship to R.L.H.), by Charles University in Prague (SVV 260291 ) and the Erasmus+ programme of the European Union (traineeship and study stay for L.H.), by the University of Birmingham (studentship to G.M.), and by Cardiff University through a President's Research Scholarship (to A.A.).

\section{ABBREVIATIONS}

DHFR, dihydrofolate reductase; EcDHFR, DHFR from E. coli; $\mathrm{H}_{2} \mathrm{~F}$, 7,8-dihydrofolate; $\mathrm{H}_{4} \mathrm{~F}$, 5,6,7,8-tetrahydrofolate; IPTG, isopropyl $\beta$-D-thiogalactopyranoside; LcDHFR, DHFR from $L$. casei; $\mathrm{NADP}^{+}$, nicotinamide adenine dinucleotide phosphate; $\mathrm{NADPH}$, nicotinamide adenine dinucleotide phosphate (reduced form); NADPD, $4 R-{ }^{2} \mathrm{H}-\mathrm{NADPH}$; PDB, Protein Data Bank; TbADH, alcohol dehydrogenase from Th. brockii; TmDHFR, DHFR from T. maritima. 


\section{REFERENCES}

(1) Fierke, C. A., Johnson, K. A., and Benkovic, S. J. (1987) Construction and Evaluation of the Kinetic Scheme Associated with Dihydrofolate Reductase from Escherichia coli. Biochemistry 26, 40854092.

(2) Benkovic, S. J., Fierke, C. A., and Naylor, A. M. (1988) Insights into Enzyme Function from Studies on Mutants of Dihydrofolate Reductase. Science 239, 1105-1110.

(3) Gekko, K., Yamagami, K., Kunori, Y., Ichihara, S., Kodama, M., and Iwakura, M. (1993) Effects of point mutation in a flexible loop on the stability and enzymatic function of escherichia coli dihydrofolate reductase. J. Biochem. 113, 74-80.

(4) Sawaya, M. R., and Kraut, J. (1997) Loop and subdomain movements in the mechanism of Escherichia coli dihydrofolate reductase: crystallographic evidence. Biochemistry 36, 586-603.

(5) Kitahara, R., Sareth, S., Yamada, H., Ohmae, E., Gekko, K., and Akasaka, K. (2000) High pressure NMR reveals active-site hinge motion of folate-bound Escherichia coli dihydrofolate reductase. Biochemistry 39, 12789-12795.

(6) Agarwal, P. K., Billeter, S. R., Rajagopalan, P. T. R., Benkovic, S. J., and Hammes-Schiffer, S. (2002) Network of coupled promoting motions in enzyme catalysis. Proc. Natl. Acad. Sci. U. S. A. 99, 27942799.

(7) Rod, T. H., Radkiewicz, J. L., and Brooks, C. L. (2003) Correlated motion and the effect of distal mutations in dihydrofolate reductase. Proc. Natl. Acad. Sci. U. S. A. 100, 6980-6985.

(8) Sikorski, R. S., Wang, L., Markham, K. A., Rajagopalan, P. T. R., Benkovic, S. J., and Kohen, A. (2004) Tunneling and coupled motion in the Escherichia coli dihydrofolate reductase catalysis. J. Am. Chem. Soc. 126, 4778-4779.

(9) Boehr, D. D., McElheny, D., Dyson, H. J., and Wright, P. E. (2006) The dynamic energy landscape of dihydrofolate reductase catalysis. Science (Washington, DC, U. S.) 313, 1638-1642.

(10) Wang, L., Goodey, N. M., Benkovic, S. J., and Kohen, A. (2006) The role of enzyme dynamics and tunnelling in catalysing hydride transfer: studies of distal mutants of dihydrofolate reductase. Philos. Trans. R. Soc., B 361, 1307-1315.

(11) Liu, H. B., and Warshel, A. (2007) The catalytic effect of dihydrofolate reductase and its mutants is determined by reorganization energies. Biochemistry 46, 6011-6025.

(12) Thielges, M. C., Case, D. A., and Romesberg, F. E. (2008) Carbon-Deuterium Bonds as Probes of Dihydrofolate Reductase. J. Am. Chem. Soc. 130, 6597-6603.

(13) Allemann, R. K., Evans, R. M., and Loveridge, E. J. (2009) Probing coupled motions in enzymatic hydrogen tunnelling reactions. Biochem. Soc. Trans. 37, 349-353.

(14) Loveridge, E. J., Tey, L. H., and Allemann, R. K. (2010) Solvent Effects on Catalysis by Escherichia coli Dihydrofolate Reductase. J. Am. Chem. Soc. 132, 1137-1143.

(15) Adamczyk, A. J., Cao, J., Kamerlin, S. C. L., and Warshel, A. (2011) Catalysis by dihydrofolate reductase and other enzymes arises from electrostatic preorganization, not conformational motions. Proc. Natl. Acad. Sci. U. S. A. 108, 14115-14120.

(16) Arai, M., Iwakura, M., Matthews, C. R., and Bilsel, O. (2011) Microsecond Subdomain Folding in Dihydrofolate Reductase. J. Mol. Biol. 410, 329-342.

(17) Boekelheide, N., Salomon-Ferrer, R., and Miller, T. F., III (2011) Dynamics and dissipation in enzyme catalysis. Proc. Natl. Acad. Sci. U. S. A. 108, 16159-16163.

(18) Loveridge, E. J., Behiry, E. M., Guo, J., and Allemann, R. K. (2012) Evidence that a 'dynamic knockout' in Escherichia coli dihydrofolate reductase does not affect the chemical step of catalysis. Nat. Chem. 4, 292-297.

(19) Weikl, T. R., and Boehr, D. D. (2012) Conformational selection and induced changes along the catalytic cycle of Escherichia coli dihydrofolate reductase. Proteins: Struct., Funct., Genet. 80, 2369-2383.

(20) Luk, L. Y. P., Javier Ruiz-Pernia, J., Dawson, W. M., Roca, M., Loveridge, E. J., Glowacki, D. R., Harvey, J. N., Mulholland, A. J., Tuñón, I., Moliner, V., and Allemann, R. K. (2013) Unraveling the role of protein dynamics in dihydrofolate reductase catalysis. Proc. Natl. Acad. Sci. U. S. A. 110, 16344-16349.

(21) Dams, T., Auerbach, G., Bader, G., Jacob, U., Ploom, T., Huber, R, and Jaenicke, R. (2000) The crystal structure of dihydrofolate reductase from Thermotoga maritima: Molecular features of thermostability. J. Mol. Biol. 297, 659-672.

(22) Dams, T., Bohm, G., Auerbach, G., Bader, G., Schurig, H., and Jaenicke, R. (1998) Homo-dimeric recombinant dihydrofolate reductase from Thermotoga maritima shows extreme intrinsic stability. Biol. Chem. 379, 367-371.

(23) Wilquet, V., Gaspar, J. A., van de Lande, M., van de Casteele, M., Legrain, C., Meiering, E. M., and Glansdorff, N. (1998) Purification and characterization of recombinant Thermotoga maritima dihydrofolate reductase. Eur. J. Biochem. 255, 628-637.

(24) Maglia, G., Javed, M. H., and Allemann, R. K. (2003) Hydride transfer during catalysis by dihydrofolate reductase from Thermotoga maritima. Biochem. J. 374, 529-535.

(25) Loveridge, E. J., Rodriguez, R. J., Swanwick, R. S., and Allemann, R. K. (2009) Effect of Dimerisation on the Stability and Catalytic Activity of Dihydrofolate Reductase from the Hyperthermophile Thermotoga maritima. Biochemistry 48, 5922-5933.

(26) Loveridge, E. J., and Allemann, R. K. (2010) The Temperature Dependence of the Kinetic Isotope Effects of Dihydrofolate Reductase from Thermotoga maritima Is Influenced by Intersubunit Interactions. Biochemistry 49, 5390-5396.

(27) Guo, J., Loveridge, E. J., Luk, L. Y. P., and Allemann, R. K. (2013) Effect of Dimerization on Dihydrofolate Reductase Catalysis. Biochemistry 52, 3881-3887.

(28) Loveridge, E. J., Maglia, G., and Allemann, R. K. (2009) The role of arginine 28 in catalysis by dihydrofolate reductase from the hyperthermophile Thermotoga maritima. ChemBioChem 10, 26242627.

(29) Blakley, R. L. (1969) The Biochemistry of Folic Acid and other Pteridines, Elsevier, New York.

(30) Tamura, T., and Picciano, M. F. (2006) Folate and human reproduction. Am. J. Clin. Nutr. 83, 993-1016.

(31) Posner, B. A., Li, L. Y., Bethell, R., Tsuji, T., and Benkovic, S. J. (1996) Engineering specificity for folate into dihydrofolate reductase from Escherichia coli. Biochemistry 35, 1653-1663.

(32) Charlton, P. A., Young, D. W., Birdsall, B., Feeney, J., and Roberts, G. C. K. (1979) Stereochemistry of Reduction of Folic Acid Using Dihydrofolate Reductase. J. Chem. Soc., Chem. Commun., 922924.

(33) Charlton, P. A., Young, D. W., Birdsall, B., Feeney, J., and Roberts, G. C. K. (1985) Stereochemistry of Reduction of the Vitamin Folic Acid by Dihydrofolate Reductase. J. Chem. Soc., Perkin Trans. 1, 1349-1353.

(34) Gready, J. E. (1980) Dihydrofolate reductase: binding of substrates and inhibitors and catalytic mechanism. Adv. Pharmacol. 17, 37-102.

(35) Gready, J. E. (1984) Theoretical studies on pteridines. J. Mol. Struct.: THEOCHEM 109, 231-244.

(36) Gready, J. E. (1985) Theoretical studies on the activation of the pterin cofactor in the catalytic mechanism of dihydrofolate reductase. Biochemistry 24, 4761-4766.

(37) Wan, Q., Bennett, B. C., Wilson, M. A., Kovalevsky, A., Langan, P., Howell, E. E., and Dealwis, C. (2014) Toward resolving the catalytic mechanism of dihydrofolate reductase using neutron and ultrahigh-resolution X-ray crystallography. Proc. Natl. Acad. Sci. U. S. A. $111,18225-18230$.

(38) Blakley, R. (1960) Crystalline dihydropteroylglutamic acid. Nature 188, 231-232.

(39) Loveridge, E. J., and Allemann, R. K. (2011) Effect of pH on Hydride Transfer by Escherichia coli Dihydrofolate Reductase. ChemBioChem 12, 1258-1262.

(40) Hay, S., Evans, R. M., Levy, C., Loveridge, E. J., Wang, X., Leys, D., Allemann, R. K., and Scrutton, N. S. (2009) Are the catalytic properties of enzymes from piezophilic organisms pressure adapted? ChemBioChem 10, 2348-53. 
(41) Swanwick, R. S., Maglia, G., Tey, L., and Allemann, R. K. (2006) Coupling of protein motions and hydrogen transfer during catalysis by Escherichia coli dihydrofolate reductase. Biochem. J. 394, 259-265.

(42) Stone, S. R., and Morrison, J. F. (1982) Kinetic mechanism of the reaction catalyzed by dihydrofolate reductase from Escherichia coli. Biochemistry 21, 3757-3765.

(43) Dann, J. G., Ostler, G., Bjur, R. A., King, R. W., Scudder, P., Turner, P. C., Roberts, G. C., and Burgen, A. S. (1976) Large-scale purification and characterization of dihydrofolate reductase from a methotrexate-resistant strain of Lactobacillus casei. Biochem. J. 157, 559-571.

(44) Maglia, G., and Allemann, R. K. (2003) Evidence for environmentally coupled hydrogen tunneling during dihydrofolate reductase catalysis. J. Am. Chem. Soc. 125, 13372-13373.

(45) Chen, Y. Q., Kraut, J., Blakley, R. L., and Callender, R. (1994) Determination by Raman-Spectroscopy of the $\mathrm{Pk}(\mathrm{a})$ of N5 of Dihydrofolate Bound to Dihydrofolate Reductase - Mechanistic Implications. Biochemistry 33, 7021-7026.

(46) Chen, Y. Q., Kraut, J., and Callender, R. (1997) pH-dependent conformational changes in Escherichia coli dihydrofolate reductase revealed by Raman difference spectroscopy. Biophys. J. 72, 936-941.

(47) Loveridge, E. J., Evans, R. M., and Allemann, R. K. (2008) Solvent Effects on Environmentally Coupled Hydrogen Tunnelling During Catalysis by Dihydrofolate Reductase from Thermotoga maritima. Chem. - Eur. J. 14, 10782-10788.

(48) Bennett, B. D., Kimball, E. H., Gao, M., Osterhout, R., Van Dien, S. J., and Rabinowitz, J. D. (2009) Absolute metabolite concentrations and implied enzyme active site occupancy in Escherichia coli. Nat. Chem. Biol. 5, 593-599.

(49) Tey, L.-H., Loveridge, E. J., Swanwick, R. S., Flitsch, S. L., and Allemann, R. K. (2010) Highly site-selective stability increases by glycosylation of dihydrofolate reductase. FEBS J. 277, 2171-2179.

(50) Bolla, J. R., Su, C.-C., Delmar, J. A., Radhakrishnan, A., Kumar, N., Chou, T.-H., Long, F., Rajashankar, K. R., and Yu, E. W. (2015) Crystal structure of the Alcanivorax borkumensis YdaH transporter reveals an unusual topology. Nat. Commun. 6, 6874.

(51) Rohlman, C. E., and Matthews, R. G. (1990) Role of purine biosynthetic intermediates in response to folate stress in Escherichia coli. J. Bacteriol. 172, 7200-7210.

(52) Kwon, Y. K., Lu, W., Melamud, E., Khanam, N., Bognar, A., and Rabinowitz, J. D. (2008) A domino effect in antifolate drug action in Escherichia coli. Nat. Chem. Biol. 4, 602-608.

(53) Tey, L. H., Loveridge, E. J., Swanwick, R. S., Flitsch, S. L., and Allemann, R. K. (2010) Highly site-selective stability increases by glycosylation of dihydrofolate reductase. FEBS J. 277, 2171-2179.

(54) Huber, R., Langworthy, T. A., Konig, H., Thomm, M., Woese, C. R., Sleytr, U. B., and Stetter, K. O. (1986) Thermotoga maritima sp. nov. represents a new genus of unique extremely thermophilic eubacteria growing up to 90 degrees C. Arch. Microbiol. 144, 324-333.

(55) Maglia, G., Javed, M. H., and Allemann, R. K. (2003) Hydride transfer during catalysis by dihydrofolate reductase from Thermotoga maritima. Biochem. J. 374, 529-535. 